\title{
Collaborative Development Planning Model of Supporting Product in Platform Innovation Ecosystem
}

\author{
Wei Zhang, ${ }^{1,2}$ Hamid Reza Karimi, ${ }^{3}$ Qingpu Zhang, ${ }^{1,2}$ and Shaobo $\mathrm{Wu}^{4}$ \\ ${ }^{1}$ School of Management, Harbin Institute of Technology, Harbin 150001, China \\ ${ }^{2}$ HIT-UMKC Institute for Entrepreneurship and Innovation, Harbin Institute of Technology, Harbin 150030, China \\ ${ }^{3}$ Department of Engineering, Faculty of Engineering and Science, University of Agder, 4898 Grimstad, Norway \\ ${ }^{4}$ School of Business Planning, Chongqing Technology and Business University, Chongqing 400067, China
}

Correspondence should be addressed to Shaobo Wu; wushaobo1979@163.com

Received 28 February 2014; Accepted 17 March 2014; Published 3 April 2014

Academic Editor: Mohammed Chadli

Copyright (C) 2014 Wei Zhang et al. This is an open access article distributed under the Creative Commons Attribution License, which permits unrestricted use, distribution, and reproduction in any medium, provided the original work is properly cited.

\begin{abstract}
In order to improve the market value of the product, the platform enterprise often participates in the development process of supporting product of emerging industry's platform innovation ecosystem. This paper puts forward a revenue sharing contract between the platform company and the supporting company by creating a collaborative development model of the supporting product in the ecosystem, and this paper studies the platform enterprise investment resource property's (complementary or substitution) impact on the supporting enterprise R\&D efforts and the revenue sharing factor and analyzes collaborative development mechanism of supporting product of emerging industry platform innovation ecosystem. The research indicates that when platform enterprise and supporting enterprise's resources are complementary, the supporting enterprise R\&D effort level and revenue sharing coefficient increase as the platform company's investment increases. When platform enterprise and supporting enterprise's resources are substitutive, the supporting enterprise's R\&D effort level and revenue sharing coefficient decrease as the platform company's investment increases.
\end{abstract}

\section{Introduction}

In today's increasingly competitive market, technological innovation based on innovative platform is increasingly important for emerging industries (such as personal computers, computer operating systems, and the Internet industry). In order to meet the diverse needs of users and have access to external network economic effects, the platform owners usually use the strategy opening platform technology interface and encourage external innovation organizations (such as enterprises, universities, and research institutes) to conduct innovation of complementary components based on product platform [1]. Technologies innovative platform and a range of complementary external components together provide users with a complete set of product or service solution [2]. For example, in order to improve the product innovation speed and only focus on the research and development of platform technology (microprocessor), the Internet companies seek the outside innovation organizations to develop the software through freely opening the interface of platform technology and close integration between hardware, middleware, and application software that forms the overall solution and constitutes a platform for innovation ecosystems.

Hence, the platform innovation ecosystem is an interdependent partnership established by the core innovation enterprises which opens innovation platform interface, and other participants who have the product technology supplied the disadvantages of core enterprise, such as companies, universities, research institutes, upstream suppliers, and downstream distributors, users, and even competitors [3-5]. Each innovation organization forms group relations which is similar with ecosystems within the platform innovation; they coexist, mutually parasitic, and work together to create value for consumers. In platform innovation ecosystems, the market value is decided not only by core platform products but also by relevant supporting complementary components. For example, in the aircraft platform innovation ecosystem in which Airbus is the core enterprise, the influence for the 
product value is from not only the fuselage structure done by Airbus but also the aircraft engines and other supporting complementary components. So the technology innovation of ancillary products is so important, and platform companies are often also involved in the development of complementary products and cooperate with the supporting enterprises. In addition to focusing on the development of platform architecture, Airbus also is involved in the development of aircraft engines, thus increasing the value of system products.

There are already a lot of researches on platform innovation ecosystem. Baldwin and Clark [6] and Schilling [7] studied the methods about engineering design, platform architecture, and modular innovation in platform ecosystem. Suarez and Battles [8] and Murmann and Frenken [9] analyzed evolution of platform technology and the technical advantages of platform innovation. Perrons [10] studied the platform enterprises' process on trust and control mechanisms that maintained the leading position in platform innovation ecosystem. Adner and Kapoor [11] conducted the empirical research on the technology during 1962 and 2005 years in the global semiconductor CD equipment industry and found that the external challenges of core enterprise innovation performance in innovation ecosystem depends on not only the enterprises scale in ecosystem but also their relative ecology position. Nambisan and Baron [12] studied the main functions of the core enterprise in platform innovation ecosystem, the selection criteria of cooperation members as well as cooperation rules. Ceccagnoli et al. [13] studied the motivation of outside supporting companies that added into platform innovation ecosystem, including quickly accessing to the established markets, acquiring the corresponding brand and reputation advantage, and getting the chances to learn technical knowledge and achieve IPO in the capital market. S. Scholten and U. Scholten [14] studied the control mechanisms of platform innovation ecosystem.

From the existing literature, the study of multiplatform innovation ecosystem focused on architecture, leadership mechanism, the mechanisms forming the advantages, and operation mechanism. There are fewer studies on collaborative development of complementary products in platform innovation ecosystem, especially for the supporting product development of platform companies. We also cannot find the suitable theories to support the influencing relationship between the nature (complementary or alternative) of the platform enterprise resources and development efforts and revenue sharing coefficient of supporting enterprise. Hence, our study has some practical and theoretical value.

The research object in this paper is the collaborative development of supporting product in platform innovation ecosystem under asymmetric information. In this study, the platform enterprises look forward to reducing the costs of supporting enterprise and improving investment enthusiasm for supporting product development by the behaviors of ancillary products development. As the efforts of supporting product development are unobservable by supporting enterprises, they often use this information advantage to bring moral hazard. Previous studies generally use the revenue sharing contract in principal-agent theory to solve such moral hazard problem, but there is rarely literature involved in principal participation in agent's production and development activities. In this paper, we established the principalagent model under platform enterprises participating in innovation, proposed revenue-sharing contract between the supporting enterprises and platform enterprises, studied the influence of nature (complementary or alternative) of platform enterprises' resource inputs on research and development effort and revenue sharing coefficient of supporting business, and finally analyzed collaborative development mechanisms of supporting products in emerging industry platform innovation ecosystem.

\section{Model Assumptions of Supporting Product Collaborative Development}

We assumed that a platform innovation ecosystem consists of a platform enterprise which is involved in developing platform product technology and a supporting enterprise which is involved in developing supporting product [15-17]. These two types of enterprises combine the platform product and supporting product and then provide the consumers with a complete set of product solutions. The collaboration of platform enterprise and supporting enterprise can be shown from the following processes.

(1) Contract Signing. Platform enterprise first proposes cooperation contract to supporting enterprise; the principal terms should be included in revenue sharing mechanisms and the participation commitments of platform enterprise. Supporting enterprise computes its expected revenue under the contract; if the expected benefits outweigh the retained earnings, it chooses the cooperation or refuses to accept the contract.

(2) Supporting Product Production. When the platform enterprise achieves its commitment to the investment on supporting product, the supporting enterprise begins to choose its effort on developing supporting product and implement the cooperation agreement.

(3) Income Payments. After the platform enterprise and supporting enterprise collaboratively finish the development of complementary products, the platform enterprise should pay the supporting enterprise.

In order to facilitate conducting our research, we make the following assumptions.

(1) Output of supporting products are affected by the efforts of research and development (R\&D) the supporting enterprise paid and external random factors; output function is $\pi=\mu e+\varepsilon$, wherein $e$ is the effort of supporting enterprise $\mathrm{R} \& \mathrm{D}$; platform enterprise cannot observe the effort of supporting enterprise. $\mu$ is the influencing of supporting enterprise effort on supporting product and $\varepsilon$ is the influencing of external random on production, $\varepsilon \sim N(0,1)$. We have $E(\pi)=E(\mu e+\varepsilon)=\mu e, \operatorname{var}(\pi)=\sigma^{2}$.

(2) The production cost of supporting enterprise is affected by its own effort of R\&D and the influencing 
of platform enterprise on supporting enterprise; its production cost function is a quadratic function $C(e, T), T$ is the quantity of the resource, such as the human and material resources invested to develop supporting product by platform enterprise, and its investment cost is $(1 / 2) \kappa T^{2}$ ( $\kappa$ is a constant which is greater than 0 ). The production cost function of supporting enterprise should meet the conditions $\partial C(e, T) / \partial e>0, \partial^{2} C(e, T) / \partial^{2} e>0$, which presents that in case of the investment of platform enterprise not changing, with the effort of supporting enterprise investment increased, its production cost would be increased but the speed of the addition will be faster; it meets the condition $\partial^{3} C(e, T) / \partial^{3} e=0$ under the quadratic function. Furthermore, the production cost of supporting enterprise should meet the condition $\partial C(e, T) / \partial T<0$, which presents that in case of the effort of supporting enterprise R\&D staying constant, with the investment of platform enterprise increased, the cost of supporting enterprise will be reduced.

(3) The contract signed by platform enterprise and supporting enterprise is included in the contents fixed payment and distribution of benefits, assuming the form of contract is $R(\pi)=a+b \pi(a>0, b>0)$; $a$ is the fixed payment the platform enterprise pays to supporting enterprise and $b$ is the distribution ratio of benefits gained by supporting enterprise.

\section{Model Establishment of Supporting Product Collaborative Development}

According to the previous assumptions, if the platform enterprise is risk-neutral, while the supporting enterprise is riskaverse, the utility function is with risk-averse characteristics $u(R)=-e^{\rho R} ; \rho$ is the amount of risk aversion and the risk costs of supporting enterprise are $(1 / 2) \rho b^{2} \sigma^{2}$. The revenue function of platform enterprise can be expressed as

$$
V_{1}=\pi-R(\pi)-\frac{1}{2} \kappa T^{2}=(1-b) \mu e-a-\frac{1}{2} \kappa T^{2} .
$$

The revenue function of supporting enterprise can be expressed as

$$
\begin{aligned}
V_{2} & =E[R(\pi)-C(e, T)]-\frac{1}{2} \rho b^{2} \sigma^{2} \\
& =a+b \mu e-C(e, T)-\frac{1}{2} \rho b^{2} \sigma^{2} .
\end{aligned}
$$

In the decision process of investing the month into developing the supporting product by platform enterprise, according to rational economic man hypothesis, it should maximize its own interests as a decision objective. Therefore, the problem of the platform enterprise is to choose $(a, b, T, e)$ maximizing their certainty equivalent income:

$$
\max _{(a, b, T, e)}(1-b) \mu e-a-\frac{1}{2} \kappa T^{2}
$$

assuming that certainty income corresponding to reservation utility of supporting enterprise is $w_{0}\left(w_{0}>0\right)$.

Supporting enterprise accepts the conditions of the contract provided by enterprise companies; the conditions it involved in the development of supporting products are that its benefits are greater that certainty income corresponding to the reservation utility, so the participation constraint condition (IR) is

$$
a+b \mu e-C(e, T)-\frac{1}{2} \rho b^{2} \sigma^{2} \geq w_{0} .
$$

As the platform enterprise cannot observe supporting enterprise's effort of investment $e$ and natural status $\varepsilon$, for any given incentive contract in advance, the supporting enterprise always chooses the effort $e$ maximizing their expected utility function; therefore, the desirable effort $e$ of platform enterprise can only be achieved through inspiring utilitymaximizing behavior of supporting enterprise, which must be met with incentive compatibility constraints condition (IC):

$$
e \in \arg \max \left[a+b \mu e-C(e, T)-\frac{1}{2} \rho b^{2} \sigma^{2}\right] .
$$

Based on the above (3) (5), we can transform the problem that platform enterprise maximizes its own certainty equivalent income into a planning problem $\mathrm{H1}$ :

$$
\begin{array}{ll}
\max _{(a, b, T, e)} & (1-b) \mu e-a-\frac{1}{2} \kappa T^{2} \\
\text { s.t. } & (\mathrm{IR}) a+b \mu e-C(e, T)-\frac{1}{2} \rho b^{2} \sigma^{2} \geq w_{0} \\
& (\mathrm{IC}) e \in \arg \max \left[a+b \mu e-C(e, T)-\frac{1}{2} \rho b^{2} \sigma\right] .
\end{array}
$$

\section{Model Solution and Analysis}

In the planning problem H1, only when the platform enterprise pays the lowest level $w_{0}$, the supporting enterprise will take part in the development of supporting products, so formula (4) is with equality; it can be rewritten as

$$
a+b \mu e-C(e, T)-\frac{1}{2} \rho b^{2} \sigma^{2}=w_{0} .
$$

Transforming the form of formula (4):

$$
a=w_{0}-b \mu e+C(e, T)+\frac{1}{2} \rho b^{2} \sigma^{2} .
$$

Substituting formula (8) into the objective function of formula (3), eliminating $a$, we have

$$
V_{1}=\mu e-\frac{1}{2} \rho b^{2} \sigma^{2}-C(e, T)-\frac{1}{2} \kappa T^{2}
$$

Solving the incentive compatibility constraints conditions of (5) and a derivation of $e$, we have

$$
\mu b-\frac{\partial C(e, T)}{\partial e}=0 .
$$


According to formula (10), we can get $b=\partial C(e, T) / \mu \partial e$, and substituting formula (8) into it and eliminating $b$, we have a new optimization problem $\mathrm{H} 2$ :

$$
\max _{(T, e)} \mu e-\frac{\rho \sigma^{2}}{2 \mu^{2}}\left[\frac{\partial C(e, T)}{\partial e}\right]^{2}-C(e, T)-\frac{1}{2} \kappa T^{2}-w_{0} .
$$

In formula (11), by giving the specific expression of $C(e, T)$, it is easy to obtain the optimal investment $T$ and the effort $e$ of supporting enterprise. And then by substituting into (10), we can obtain the revenue sharing coefficient in the contract. However, our concern is the influence of nature (complementary or alternative) of platform enterprises' resource inputs on research and development effort and revenue sharing coefficient of supporting business, so we need to establish the relationship between inputs $T$ for supporting product by platform enterprise and R\&D effort $e$ paid by supporting enterprise.

In the formula (11), get a derivation for $e$ and set it to zero; the optimal first-order conditions can be obtained as follows:

$$
\mu-\frac{\rho \sigma^{2}}{2 \mu^{2}} \cdot \frac{\partial C(e, T)}{\partial e} \cdot \frac{\partial^{2} C(e, T)}{\partial^{2} e}-\frac{\partial C(e, T)}{\partial e}=0 .
$$

Formula (11) presents inputs $T$ of platform enterprise; we can obtain the effort $e$ of supporting enterprise by employing formula (12), in which we can see $e$ as the function of $T$. Using a derivation for $T$, we can obtain the influence of platform enterprise inputs $T$ on the level of effort $e$ of supporting enterprise:

$$
\begin{gathered}
\left\{\frac{\rho \sigma^{2}}{2 \mu^{2}} \cdot\left[\frac{\partial^{2} C(e, T)}{\partial^{2} e}\right]^{2}+\frac{\rho \sigma^{2}}{2 \mu^{2}} \cdot \frac{\partial C(e, T)}{\partial e} \cdot \frac{\partial^{3} C(e, T)}{\partial^{3} e}\right. \\
\left.+\frac{\partial^{2} C(e, T)}{\partial^{2} e}\right\} \frac{\partial e}{\partial T} \\
+\left[\frac{\rho \sigma^{2}}{2 \mu^{2}} \cdot \frac{\partial^{2} C(e, T)}{\partial^{2} e} \cdot \frac{\partial^{2} C(e, T)}{\partial e \partial T}+\frac{\rho \sigma^{2}}{2 \mu^{2}} \cdot \frac{\partial C(e, T)}{\partial e}\right. \\
\left.\cdot \frac{\partial^{3} C(e, T)}{\partial^{2} e \partial T}+\frac{\partial^{2} C(e, T)}{\partial e \partial T}\right]=0 .
\end{gathered}
$$

As the cost function $C(e, T)$ is a quadratic function, obtain $\partial^{3} C(e, T) / \partial^{3} e=0$, so using formula (13), we have

$$
\begin{aligned}
\frac{\partial e}{\partial T}= & -\left(\frac{\rho \sigma^{2}}{2 \mu^{2}} \cdot \frac{\partial^{2} C(e, T)}{\partial^{2} e} \cdot \frac{\partial^{2} C(e, T)}{\partial e \partial T}+\frac{\rho \sigma^{2}}{2 \mu^{2}}\right. \\
& \left.\cdot \frac{\partial C(e, T)}{\partial e} \cdot \frac{\partial^{3} C(e, T)}{\partial^{2} e \partial T}+\frac{\partial^{2} C(e, T)}{\partial e \partial T}\right) \\
& \times\left(\frac{\rho \sigma^{2}}{2 \mu^{2}} \cdot\left[\frac{\partial^{2} C(e, T)}{\partial^{2} e}\right]^{2}+\frac{\partial^{2} C(e, T)}{\partial^{2} e}\right)^{-1} .
\end{aligned}
$$

Considering the above analyses, we will analyze the influence of nature (complementary or alternative) of platform enterprises' resource inputs on $\mathrm{R} \& \mathrm{D}$ effort of supporting business based on formula (14). In previous assumptions, $\partial C(e, T) / \partial e>0, \partial^{2} C(e, T) / \partial^{2} e>0$, so the positive and negative of formula (14) depend on the positive and negative of $\partial^{2} C(e, T) / \partial e \partial T$ and $\partial^{3} C(e, T) / \partial^{2} e \partial T$. In the cost function of supporting enterprise $C(e, T), \partial C(e, T) / \partial e$ is the marginal cost of effort paid by supporting enterprise, and $\partial^{2} C(e, T) / \partial e \partial T$ is the influence of platform enterprise resource inputs on the marginal cost of effort paid by supporting enterprise. If $\partial^{2} C(e, T) / \partial e \partial T<0$, it presents that the marginal cost of effort paid by supporting enterprise will reduce with the inputs of platform enterprise; that is, the inputs of platform enterprise and supporting enterprise are complementary; if $\partial^{2} C(e, T) / \partial e \partial T>0$, it presents that the marginal cost of effort paid by supporting enterprise will increase with the inputs of platform enterprise; that is, the inputs of platform enterprise and supporting enterprise are substitutive. $\partial^{2} C(e, T) / \partial^{2} e$ is the second derivative of supporting enterprise's R\&D inputs effort, that is, the change rate of the first derivative $\partial C(e, T) / \partial e$; the geometric meaning of the first derivative is the slope of the cost curve, while the geometric meaning of the second derivative is the curvature of the cost curve.

In the complementary situation, that is, $\partial^{2} C(e, T) /$ $\partial e \partial T<0$, the more inputs the platform enterprise invests for supporting product development, the smaller the slope of $C(e, T)$ is. In order to guarantee that the slope of the cost curve $C(e, T)$ of the supporting enterprise effort under the situation of high inputs of platform enterprise is always smaller than the low inputs of platform enterprise, it has to make the curvature of the cost curve $C(e, T)$ under the situation of high inputs of platform enterprise smaller than the curvature of the cost curve $C(e, T)$ of the supporting enterprise effort under the situation of low inputs of platform enterprise, as shown in Figure 1. We can see that the cost curve of supporting enterprise in the situation of platform enterprise low inputs is obviously steeper than the situation of high inputs of platform enterprise. That is, in the complementary situation, the influence of platform enterprise inputs on the change rate of marginal cost $C(e, T)$ can meet $\partial^{3} C(e, T) / \partial^{2} e \partial T<0$ [18]. Hence, based on the previous analyses, we can know that when the inputs of platform enterprise and supporting enterprise are complementary, there are the conditions that $\partial^{2} C(e, T) / \partial e \partial T<0$ and $\partial^{3} C(e, T) / \partial^{2} e \partial T<0$. In contrast, in the substitutive situation, the cost curve of supporting enterprise in the situation of platform enterprise high inputs is obviously steeper than the situation of low inputs of platform enterprise, as shown in Figure 2; there are the conditions that $\partial^{2} C(e, T) / \partial e \partial T>0$ and $\partial^{3} C(e, T) / \partial^{2} e \partial T>$ 0 .

Considering previous assumptions and the above analyses about influence of nature (complementary or alternative) of platform enterprises resource inputs on $\mathrm{R} \& \mathrm{D}$ effort of supporting enterprise, under the complementary situation, as $\partial^{2} C(e, T) / \partial e \partial T<0, \partial^{3} C(e, T) / \partial^{2} e \partial T<0$, and $\partial C(e, T) /$ $\partial e>0, \partial^{2} C(e, T) / \partial^{2} e>0$, we have

$$
\frac{\rho \sigma^{2}}{2 \mu^{2}} \cdot\left[\frac{\partial^{2} C(e, T)}{\partial^{2} e}\right]^{2}+\frac{\partial^{2} C(e, T)}{\partial^{2} e}>0 .
$$




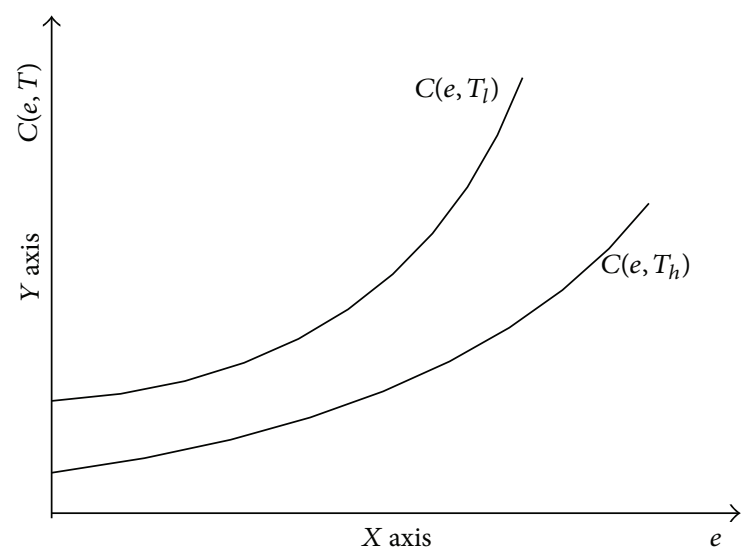

FIGURE 1: The cost curve of supporting enterprise under the complementary situation.

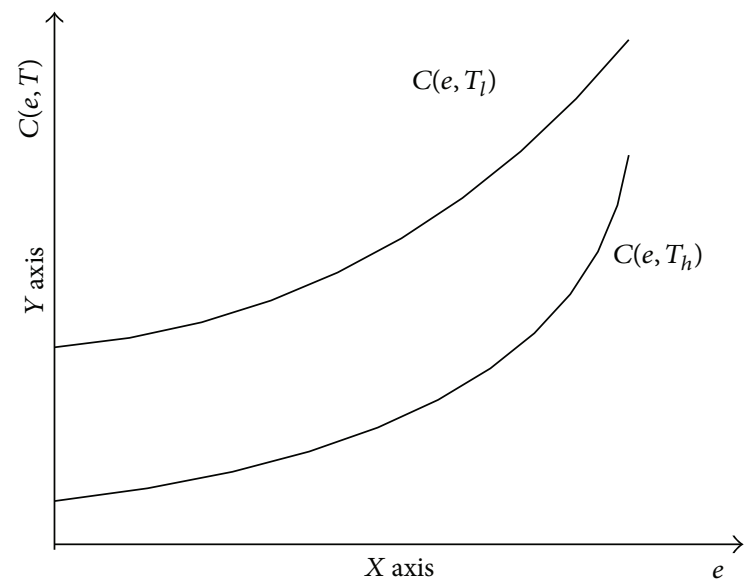

Figure 2: The cost curve of supporting enterprise under the substitutive situation.

As $\left(\rho \sigma^{2} / 2 \mu^{2}\right) \cdot\left(\partial^{2} C(e, T) / \partial^{2} e\right) \cdot\left(\partial^{2} C(e, T) / \partial e \partial T\right)<0$, $\left(\rho \sigma^{2} / 2 \mu^{2}\right) \cdot(\partial C(e, T) / \partial e) \cdot\left(\partial^{3} C(e, T) / \partial^{2} e \partial T\right)<0$, we have $\left(\rho \sigma^{2} / 2 \mu^{2}\right) \cdot\left(\partial^{2} C(e, T) / \partial^{2} e\right) \cdot\left(\partial^{2} C(e, T) / \partial e \partial T\right)+\left(\rho \sigma^{2} / 2 \mu^{2}\right) \cdot$ $(\partial C(e, T) / \partial e) \cdot\left(\partial^{3} C(e, T) / \partial^{2} e \partial T\right)+\left(\partial^{2} C(e, T) / \partial e \partial T\right)<0$.

It is easy to find that $\partial e / \partial T>0$ in formula (14).

So we can get conclusion 1 : in the new industry platform innovation ecosystem, when the inputs of platform enterprise and supporting enterprise are complementary, the level of effort paid by supporting enterprise will increase if platform enterprise increases its inputs.

Considering previous assumptions and the above analyses about influence of nature (complementary or alternative) of platform enterprises resource inputs on cost function of supporting enterprise, under the substitutive situation, as $\partial^{2} C(e, T) / \partial e \partial T>0, \partial^{3} C(e, T) / \partial^{2} e \partial T>0$, and $\partial C(e, T) /$ $\partial e>0, \partial^{2} C(e, T) / \partial^{2} e>0$, we have

$$
\frac{\rho \sigma^{2}}{2 \mu^{2}} \cdot\left[\frac{\partial^{2} C(e, T)}{\partial^{2} e}\right]^{2}+\frac{\partial^{2} C(e, T)}{\partial^{2} e}>0
$$

As $\left(\rho \sigma^{2} / 2 \mu^{2}\right) \cdot\left(\partial^{2} C(e, T) / \partial^{2} e\right) \cdot\left(\partial^{2} C(e, T) / \partial e \partial T\right)>0$, $\left(\rho \sigma^{2} / 2 \mu^{2}\right) \cdot(\partial C(e, T) / \partial e) \cdot\left(\partial^{3} C(e, T) / \partial^{2} e \partial T\right)>0$, we have $\left(\rho \sigma^{2} / 2 \mu^{2}\right) \cdot\left(\partial^{2} C(e, T) / \partial^{2} e\right) \cdot\left(\partial^{2} C(e, T) / \partial e \partial T\right)+\left(\rho \sigma^{2} / 2 \mu^{2}\right) \cdot$ $(\partial C(e, T) / \partial e) \cdot\left(\partial^{3} C(e, T) / \partial^{2} e \partial T\right)+\left(\partial^{2} C(e, T) / \partial e \partial T\right)>0$.

It is easy to find that $\partial e / \partial T<0$ in formula (14).

So we can get conclusion 2: in the new industry platform innovation ecosystem, when the inputs of platform enterprise and supporting enterprise are substitutive, the level of effort paid by supporting enterprise will reduce if platform enterprise increases its inputs.

From conclusion 1 and conclusion 2, we can know that in the new industry platform innovation ecosystem, if the resource inputs of platform enterprise and supporting enterprise are complementary in collaborative development supporting products, the participant of platform enterprise has the incentives for technology innovation inputs of supporting enterprise; the possible reason is that the increase of platform enterprise complementary inputs would increase the possibility of the success developing the supporting product. If the resource inputs of platform enterprise and supporting enterprise are substitutive in collaborative development supporting products, the inputs of platform enterprise will reduce the motivation of supporting enterprise increasing technology innovation inputs; the possible reason is that the supporting enterprise gives more hope to the platform enterprise to increase its inputs and it has a "lazy" motivation and thus is more willing to let the platform enterprise take risk arising from inputs in product development.

The following is to analyze the impact of revenue sharing coefficient $b$ on the inputs of platform enterprise; by the formula (10), we can obtain $b=\partial C(e, T) / \mu \partial e$. Establishing the relationship between $b$ and the inputs $T$ of platform enterprise, a derivation for $T$, we have

$$
\frac{\partial b}{\partial T}=\frac{1}{\mu}\left[\frac{\partial^{2} C(e, T)}{\partial^{2} e} \cdot \frac{\partial e}{\partial T}+\frac{\partial^{2} C(e, T)}{\partial e \partial T}\right] .
$$

Substituting formula (14) into formula (17), we can obtain

$$
\begin{aligned}
\frac{\partial b}{\partial T}= & -\left(\frac{\rho \sigma^{2}}{2 \mu^{2}} \cdot \frac{\partial C(e, T)}{\partial e} \cdot \frac{\partial^{3} C(e, T)}{\partial^{2} e \partial T} \cdot \frac{\partial^{2} C(e, T)}{\partial^{2} e}\right) \\
& \times\left(\mu\left\{\frac{\rho \sigma^{2}}{2 \mu^{2}} \cdot\left[\frac{\partial^{2} C(e, T)}{\partial^{2} e}\right]^{2}+\frac{\partial^{2} C(e, T)}{\partial^{2} e}\right\}\right)^{-1} .
\end{aligned}
$$

Analyzing formula (18), considering previous assumptions and the above analyses about influence of nature (complementary or alternative) of platform enterprises resource inputs on cost function of supporting enterprise, under the complementary situation, as $\partial^{2} C(e, T) / \partial e \partial T<0, \partial^{3} C(e$, $T) / \partial^{2} e \partial T<0$, and $\partial C(e, T) / \partial e>0, \partial^{2} C(e, T) / \partial^{2} e>0$, we have

$$
\begin{gathered}
\mu\left\{\frac{\rho \sigma^{2}}{2 \mu^{2}} \cdot\left[\frac{\partial^{2} C(e, T)}{\partial^{2} e}\right]^{2}+\frac{\partial^{2} C(e, T)}{\partial^{2} e}\right\}>0, \\
\frac{\rho \sigma^{2}}{2 \mu^{2}} \cdot \frac{\partial C(e, T)}{\partial e} \cdot \frac{\partial^{3} C(e, T)}{\partial^{2} e \partial T} \cdot \frac{\partial^{2} C(e, T)}{\partial^{2} e}<0, \quad \text { so } \frac{\partial b}{\partial T}>0 .
\end{gathered}
$$


So we can get conclusion 3: in the new industry platform innovation ecosystem, when the inputs of platform enterprise and supporting enterprise are complementary, the revenue sharing coefficient of supporting enterprise will increase if platform enterprise increases its inputs.

Analyzing formula (18), considering previous assumptions and the above analyses about influence of nature (complementary or alternative) of platform enterprises resource inputs on cost function of supporting enterprise, under the substitutive situation, as $\partial^{2} C(e, T) / \partial e \partial T>0, \partial^{3} C(e$, $T) / \partial^{2} e \partial T>0, \partial C(e, T) / \partial e>0$, and $\partial^{2} C(e, T) / \partial^{2} e>0$, we have

$$
\begin{gathered}
\mu\left\{\frac{\rho \sigma^{2}}{2 \mu^{2}} \cdot\left[\frac{\partial^{2} C(e, T)}{\partial^{2} e}\right]^{2}+\frac{\partial^{2} C(e, T)}{\partial^{2} e}\right\}>0, \\
\frac{\rho \sigma^{2}}{2 \mu^{2}} \cdot \frac{\partial C(e, T)}{\partial e} \cdot \frac{\partial^{3} C(e, T)}{\partial^{2} e \partial T} \cdot \frac{\partial^{2} C(e, T)}{\partial^{2} e}>0, \quad \text { so } \frac{\partial b}{\partial T}<0 .
\end{gathered}
$$

So we can get conclusion 4: in the new industry platform innovation ecosystem, when the inputs of platform enterprise and supporting enterprise are substitutive, the revenue sharing coefficient of supporting enterprise will reduce if platform enterprise increases its inputs.

From conclusion 3 and conclusion 4 we can know that in the new industry platform innovation ecosystem, when the resource inputs of platform enterprise and supporting enterprise are complementary in collaborative development supporting products, if the platform enterprise increases its inputs for developing the supporting product, it should increase the revenue sharing coefficient of supporting enterprise letting it take more risks. The possible reason is that the inputs of platform enterprise reduce the marginal cost of supporting enterprise for technology innovation and, in contrast, increase its marginal revenue, so the supporting enterprise will make its marginal cost equal to marginal revenue, and platform enterprise would like to increase revenue sharing coefficient to increase the inputs of supporting enterprise. In contrast, when the resource inputs of platform enterprise and supporting enterprise are substitutive in collaborative development supporting products, if the platform enterprise increases its inputs for developing the supporting product, it should reduce the revenue sharing coefficient of supporting enterprise letting it take fewer risks. The possible reason is that the inputs of platform enterprise may increase the marginal cost of supporting enterprise for technology innovation and, in contrast, reduce its marginal revenue. It is difficult for platform enterprise to increase the inputs of supporting enterprise by increasing revenue sharing coefficient.

\section{Conclusion}

The value of new industry platform innovation ecosystem depends on not only the effect of platform enterprise on platform product but also the value of supporting product, so platform enterprise always participates in the development of supporting product. From the previous analyses, we can find supporting enterprise R\&D effort and revenue sharing coefficient in collaborative process depending on the nature of platform enterprise inputs on supporting product.

(1) When the inputs of platform enterprise and supporting enterprise are complementary, increasing platform enterprise inputs will generate the positive incentives for supporting enterprise. In contrast, when the inputs of platform enterprise and supporting enterprise are substitutive, increasing platform enterprise inputs will generate the negative incentives for supporting enterprise. The conclusions for constructing eco-innovation platform have two inspirations: firstly, for the platform enterprises in emerging industry innovation ecosystem, they should choose partners with complementary resources in building innovation ecosystem process. For example, when IBM built innovation ecosystem, it only focused on hardware development platform; the general partners it chose are with middleware and application software development capabilities which are complementary for it.

Secondly, if in the platform innovation ecosystem the platform enterprise and supporting enterprise have separate resource substitution, platform enterprise should be less involved in the development of supporting product, because when the resources are substitutive, increasing the inputs of platform enterprise will reduce the enthusiasm of supporting enterprises, an increase of supporting enterprise "lazy" motivation; if the platform enterprise and supporting enterprise are the complementary resources, the former should increase its inputs for developing supporting product; this is because increasing inputs of platform enterprise increase the likelihood of successful product development, which also has a good incentive for supporting enterprise.

(2) When the inputs of platform enterprise and supporting enterprise are complementary, the revenue sharing coefficient of supporting enterprise will increase if platform enterprise increases its inputs. When the inputs of platform enterprise and supporting enterprise are substitutive, the revenue sharing coefficient of supporting enterprise will reduce if platform enterprise increases its inputs. Hence, in the contract design process, platform enterprise should take full account of the nature of development inputs for supporting product. Under the complementary situation, the contract should increase the proportion of variable income of supporting enterprise, reducing fixed pay part, so that the supporting enterprise should take more development risks; under the substitutive situation, the contract should reduce the proportion of variable income of supporting enterprise and increase the portion of the fixed payment, so the supporting enterprise takes less development risks. This conclusion has some theoretical reference value for the contract design of supporting product's collaborative development in new industry platform innovation ecosystem.

\section{Conflict of Interests}

The authors declare that there is no conflict of interests regarding the publication of this paper. 


\section{Acknowledgment}

This work was supported by National Natural Science Funds of China (Grant nos. 71273076, 71301065, and 71303271), Humanities and Social Sciences Youth Foundation of Chinese Ministry of Education (Grant no. 3YJC630166), and the National Social Science Foundation of China (Grant no. 12CTQ029).

\section{References}

[1] W. Zhang and Q. Zhang, "Multi-stage evaluation and selection in the formation process of complex creative solution," Quality \& Quantity, 2013.

[2] A. Gawer and M. Cusumano, "How companies become platform leaders," MIT Sloan Management Review, vol. 49, no. 2, pp. 28-35, 2008.

[3] S. Yin, H. Luo, and S. Ding, "Real-time implementation of faulttolerant control systems with performance optimization," IEEE Transactions on Industrial Electronics, vol. 64, no. 5, pp. 24022411, 2014.

[4] S. Yin, G. Wang, and H. Karimi, "Data-driven design of robust fault detection system for wind turbines," Mechatronics, 2013.

[5] W. Zhang, Q. Zhang, and H. Karimi, "Seeking the important nodes of complex networks in product R\&D team based on fuzzy AHP and TOPSIS," Mathematical Problems in Engineering, vol. 2013, Article ID 327592, 9 pages, 2013.

[6] C. Y. Baldwin and K. B. Clark, Design Rules: The Power of Modularity, MIT Press, Cambridge, Mass, USA, 2000.

[7] M. A. Schilling, "Toward a general modular systems theory and its application to interfirm product modularity," Academy of Management Review, vol. 25, no. 2, pp. 312-334, 2000.

[8] F. Suarez and F. Battles, "For technological dominance: an integrated framework," Research Policy, vol. 33, no. 2, pp. 271286, 2004.

[9] J. P. Murmann and K. Frenken, "Toward a systematic framework for research on dominant designs, technological innovations, and industrial change," Research Policy, vol. 35, no. 7, pp. 925952, 2006.

[10] R. K. Perrons, “The open kimono: how Intel balances trust and power to maintain platform leadership," Research Policy, vol. 38, no. 8, pp. 1300-1312, 2009.

[11] R. Adner and R. Kapoor, "Value creation in innovation ecosystems: how the structure of technological interdependence affects firm performance in new technology generations," Strategic Management Journal, vol. 31, no. 3, pp. 306-333, 2010.

[12] S. Nambisan and R. A. Baron, "Entrepreneurship in innovation ecosystems: entrepreneurs' self-regulatory processes and their implications for new venture success," Entrepreneurship Theory and Practice, vol. 37, no. 5, pp. 1071-1097, 2012.

[13] M. Ceccagnoli, C. Forman, P. Huang, and D. J. Wu, "Cocreation of valueina platform ecosystem: the case of enterprise software," MIS Quarterly, vol. 36, no. 1, pp. 263-290, 2012.

[14] S. Scholten and U. Scholten, "Platform-based innovation management: directing external innovational efforts in platform ecosystems," Journal of the Knowledge Economy, vol. 2, no. 3, pp. 164-184, 2012.

[15] S. Yin, S. Ding, A. Haghani, and H. Hao, "Data-driven monitoring for stochastic systems and its application on batch process," International Journal of Systems Science, vol. 44, no. 7, pp. 13661376, 2013.
[16] S. Yin, S. Ding, A. Haghani, H. Hao, and P. Zhang, "A comparison study of basic data driven fault diagnosis and process monitoring methods on the benchmark Tennessee Eastman process," Journal of Process Control, vol. 22, no. 9, pp. 1567-1581, 2012.

[17] S. Yin, X. Yang, and H. R. Karimi, "Data-driven adaptive observer for fault diagnosis," Mathematical Problems in Engineering, vol. 2012, Article ID 832836, 21 pages, 2012.

[18] A. V. Iyer, L. B. Schwarz, and S. A. Zenios, "A principal-agent model for product specification and production," Management Science, vol. 51, no. 1, pp. 106-119, 2005. 


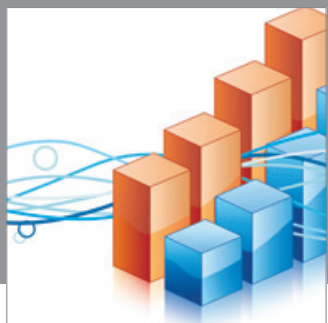

Advances in

Operations Research

mansans

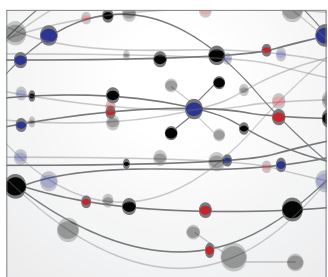

The Scientific World Journal
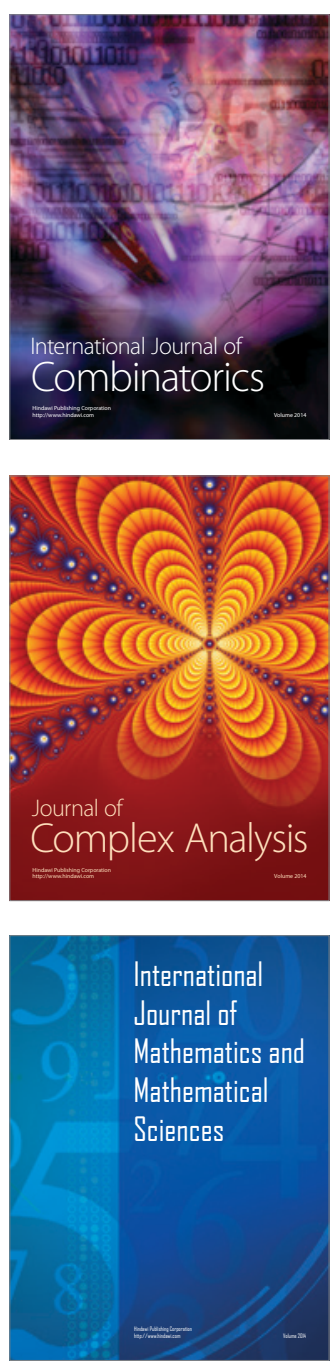
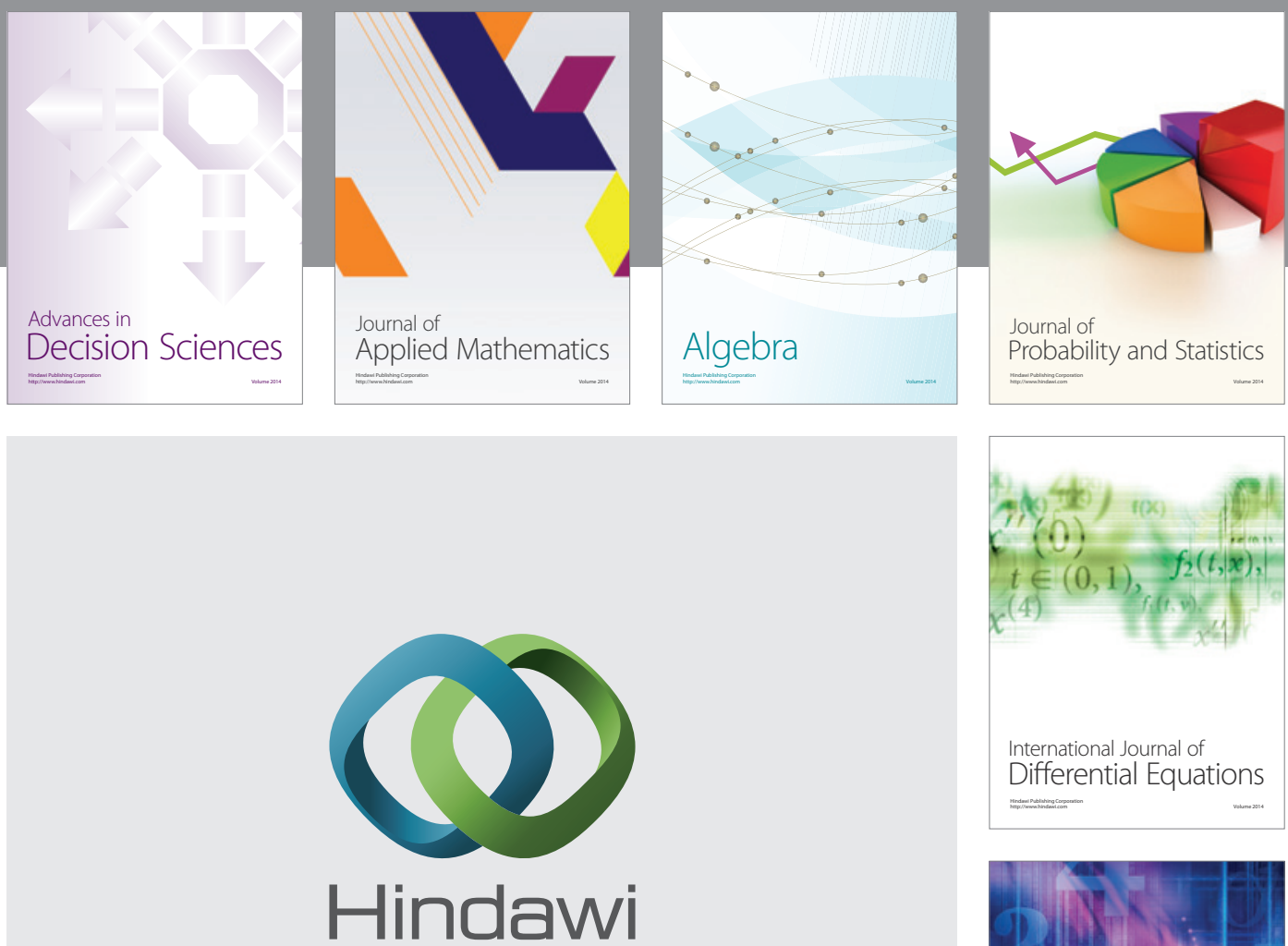

Submit your manuscripts at http://www.hindawi.com
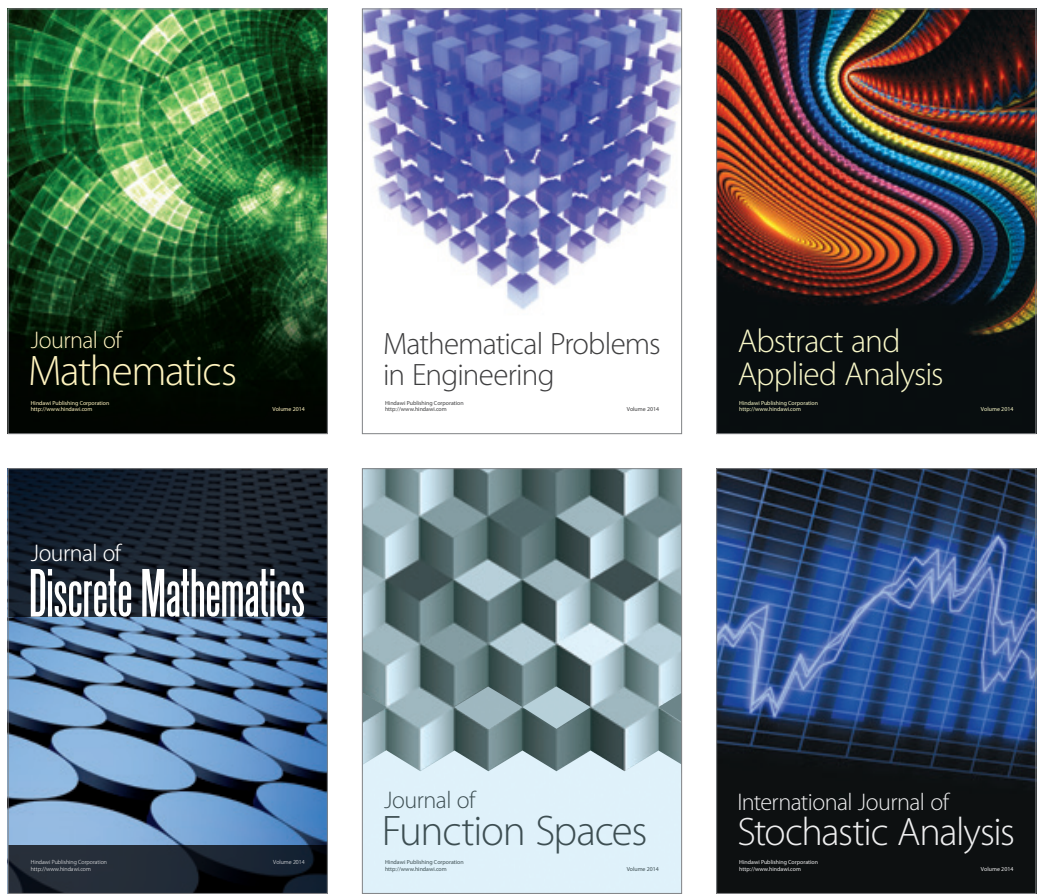

Journal of

Function Spaces

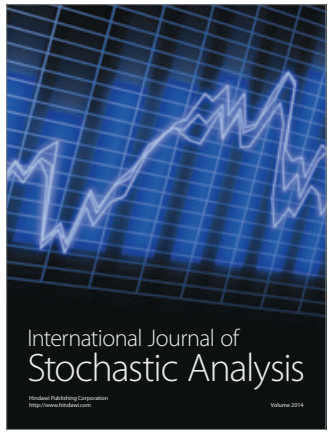

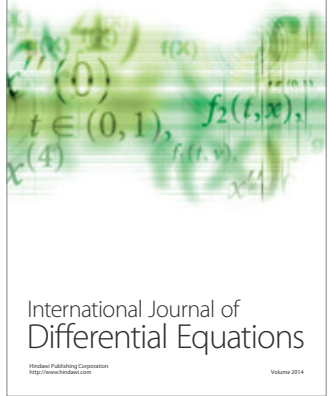
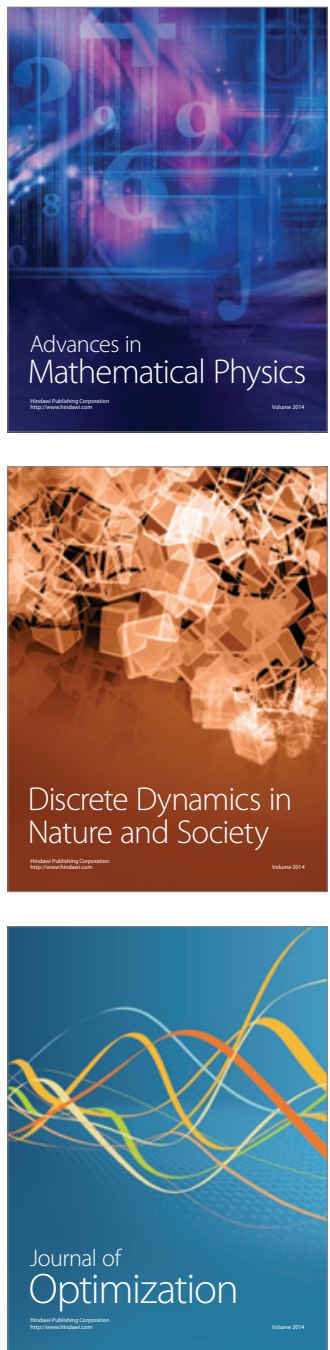